\begin{tabular}{|lr|}
\hline $\begin{array}{l}\text { Social Work/Maatskaplike Werk Vol } 51 \text { No } 2 ; \text { Issue } 6 \\
\text { http://socialwork.journals.ac.za/pub }\end{array}$ & doi:http://dx.doi.org/51-2-446 \\
\hline
\end{tabular}

PREVALENCE OF MULTIPLE ADDICTIONS AND CURRENT TREATMENT BY DRUG TREATMENT CENTRES IN DURBAN, SOUTH AFRICA

Helen Keen, Reshma Sathiparsad, Myra Taylor

Substance-use disorders (SUD) cause severe problems both globally and locally. Research suggests that multiple addictions create a more complex illness. This study investigated whether in-patients admitted for SUD at three drug treatment centres in Durban, South Africa had other, undiagnosed addictions. It utilised a three-phase concurrent mixed-methods design and initially screened for gambling and sex addiction. Results showed that, of the sample of 123 participants, $54 \%$ had either sex or gambling and $24 \%$ had both addictions which current treatment programmes neither assessed for nor treated. Recommendations include suggestions to update current assessment and treatment approaches and the need to train professional staff at drug treatment centres. 



\section{PREVALENCE OF MULTIPLE ADDICTIONS AND CURRENT TREATMENT BY DRUG TREATMENT CENTRES IN DURBAN, SOUTH AFRICA}

\section{Helen Keen, Reshma Sathiparsad, Myra Taylor}

\section{INTRODUCTION}

Substance abuse is widely acknowledged as a serious problem both internationally and in South Africa, affecting the lives of many individuals and families and society in general, and it is noted that: "it goes hand in hand with poverty, crime, reduced productivity, unemployment, dysfunctional family life, escalation of chronic diseases and premature death" (Department of Social Development, 2012:1). It is estimated by the South African Medical Research Council (MRC) that $11 \%$ of the country's population, or over five million people, will suffer from an alcohol or drug disorder in their lifetime (Makuyana, 2013). Furthermore, South Africa is listed in the World Health Organisation's (WHO) report as having one of the highest per capita rates of consumption of alcohol in Africa (WHO, 2014). Approximately $10 \%$ of people using and abusing substances will cross the line into addiction (McCauley, 2009), now referred to by the Diagnostic and Statistical Manual of Mental Disorders, Fifth Edition (DSM-5) as "substance use disorders" (SUD) (APA, 2013). These are characterised by neurological changes, repeated relapses and intense craving. People with SUD are described as having "impaired control [over drug use], social impairment, risky use and pharmacological criteria [tolerance and withdrawal]" (APA, 2013:483). Recent developments in the study of addiction suggest that nonsubstance addictions share similar causes, symptoms, consequences and even neurobiological features to SUD (Frascella, Potenza, Brown \& Childress, 2010; Shaffer, LaPlante, LaBrie, Kidman, Donato \& Stanton, 2004). Furthermore, as many as $87 \%$ of people with one addiction will have one or more additional addictions, referred to as multiple addictions (MA) (Carnes, 2008; MacLaren \& Best, 2010), and failure to treat all addictions contributes to poor treatment responses (Carnes, Murray $\&$ Charpentier, 2005; Flores, 2004). To understand better the complex issue of MA, this study was conducted amongst in-patients and professional staff at three drug treatment centres in Durban, South Africa. This article focuses on three specific objectives from a broader study on SUD and MA. Firstly, we explored the views on MA held by professional staff employed at the three drug treatment centres and determined whether the current treatment programmes offered to people with SUD assessed for and treated MA. Secondly, we ascertained the prevalence of sex and gambling addictions and, thirdly, investigated treatment outcomes from previous admissions from a survey of in-patients admitted to these centres. It was envisaged that an investigation such as this would provide useful indicators for professionals such as social workers, nurses, psychologists, psychiatrists, doctors and occupational therapists who are closely involved in the education and treatment of people affected by SUD. 


\section{BACKGROUND TO THE STUDY}

Abuse of substances in South Africa is acknowledged as either causing or being linked to numerous social problems, including domestic violence, road accidents and crime, in addition to adding to the country's already high burden of disease (Njuho \& Davids, 2011; Seggie, 2012). These factors led to the conclusion that substance abuse is the "primary underlying cause of social ills" (Department of Social Development, 2012:42). One of the measures used by the WHO to calculate the impact of disease on society is the concept of years lost due to disability (YLD). It is a formula for calculating the overall disease burden in society by measuring the impact of conditions on people living with the health condition or its consequences. Internationally, in 2012 mental and behavioural disorders (including addiction) were listed as being the major cause of years of productive life lost through living with disability (Vos, Flaxman, Naghavi \& Murray, 2012), underscoring the devastating impact that addiction in all its manifestations has upon society. A further issue regarding SUD has been the increasing trend of poly-substance use, in which people use a variety of drugs, either simultaneously, or change their drug-use patterns over time. Polysubstance use is acknowledged as creating a more complex addictive illness (Erikson, 2009; Flores, 2004) and the availability of drugs has increased in South Africa since the advent of democracy in 1994 (Van Heerden et al., 2009).

Shaffer et al. (2004) contend that addiction should be conceptualised as a syndrome with multiple causes and manifestations. Schneider (2005:75) echoes this view and urges treatment professionals to realise that: "addiction is addiction is addiction". Carnes (2008) proposes four categories of addictions, and asserts that practitioners should be mindful of the full spectrum rather than the traditionally narrow focus on the presenting symptoms which are often the more socially acceptable abuse of substances. The categories proposed are first, substances that include legal and illicit drugs; second, process addictions that include sex, food, money, gambling, work, internet use and exercise (Frascella et al., 2010; Sussman, Lisha \& Griffiths, 2001); the third category relates to relationship addictions (Doweiko, 2006); and the fourth embraces core feeling states such as rage, anger, despair and hopelessness (Bradshaw, 2005; Carnes, 2008). It has been found that these phenomena share similar neurobiological features, antecedents, symptoms and sequelae to the traditionally acknowledged addiction to substances (Hoffman, 2011; Frascella et al., 2010). The literature generally concurs that the process addictions most commonly presenting for treatment are sex and gambling (Carnes, 2008; Flores, 2004; Schneider, 2005; Sussman et al., 2011). Gambling disorder is defined in the DSM-5 as a "persistent and maladaptive gambling behaviour that disrupts personal, family and/ or vocational pursuits" (APA, 2013:586). Sex addiction is defined as "persistent, intense, sexually arousing fantasies and urges, or behaviours that cause clinically significant distress or impairment in at least one important area of functioning" (Hook, Hook, Davis, Worthington \& Penberthy, 2010:228). The literature on sex addiction notes that the internet has caused a significant escalation in the number of people presenting with out of control sexual behaviour, because it makes sexually explicit material and the opportunity for erotic connections far more accessible, at a 
lower cost and with less risk of detection (Carnes, Delminico \& Griffin, 2007; Green, Carnes, Carnes \& Weinman, 2012; Griffiths, 2012).

Screening tests have been developed to diagnose sex and gambling addictions and generally they utilise and adapt the criteria for substance dependence as listed in DSM IV-TR (Bellringer, Abbott, Coombes, Garrett \& Volberg, 2008; Carnes, Green \& Carnes, 2010; Hodgins et al., 2011; Holtgraves, 2009; Hook et al., 2010; Orford, Wardle, Griffiths, Sproston \& Erens, 2010). Carnes et al. (2010) state that in their revision of their sex addiction screening test (R-SAST) they developed a specific sub-set of questions dealing specifically with internet use for sexual purposes because of the impact of online activity on sexual behaviour.

Multiple addictions were first formally described in Miller's (1977) book entitled The addictive behaviours: treatment of alcoholism, drug abuse, smoking and obesity. Carnes reported in his 1991 publication entitled Don't Call it Love that 83\% of the 943 sex addicts in his study had at least one other addiction, with $43 \%$ of the participants meeting the criteria for chemical dependence. Subsequent research by Carnes et al. (2005) established that $87 \%$ of sex addicts in treatment $(n=1604)$ had MA with other commonly occurring addictions being eating disorders, gambling, compulsive spending and debting, compulsive working and compulsive athleticism. In 2011 a meta-analysis of research of 83 international studies of 11 addictions (three chemical and eight process addictions) found that people presenting with one addiction were highly likely to have co-occurring addictions, with concurrence rates ranging from 10 to $50 \%$ (Sussman et al., 2011).

In South Africa Bulwer (2003) conducted research with 100 pathological gamblers (pathological gambling was subsequently re-named "gambling disorder" by DSM-5 in 2013). She discovered that $30 \%$ of her sample had alcohol abuse problems, whilst $6 \%$ and $3 \%$ reported dependence upon illegal or prescription drugs respectively. Regarding process addictions, $12 \%$ reported compulsive eating, $13 \%$ compulsive spending and $11 \%$ compulsive sexual behaviour. She also found high rates of co-dependent relationships in the sample (although no percentage was given). The concept of MA is thus established in addiction research (Bradshaw, 2005; Carnes, 2008; MacLaren \& Best, 2010; Shaffer et al., 2004), and Sussman et al. (2011) note that many addictions occur in clusters that can be predicted. Furthermore, if a person has more than one addiction, they are likely to combine in specific ways to produce an illness more resistant to treatment (Carnes et al., 2005; Flores, 2004).

Recent research undertaken by Bowles, Louw and Myers (2011) evaluated the functioning of management structures at drug treatment centres throughout South Africa. Their study revealed that there was insufficient awareness and limited commitment to apply new knowledge or to introduce evidence-based practice into treatment programmes. None of the 44 centres that participated in the research had any data on treatment outcomes or relapse rates, whilst staff and management saw little need to change and adapt their existing programmes. This finding raises issues of accountability, given the resources utilised in prevention and treatment programmes and the fact that 
addiction has such a negative impact upon South African society (Department of Social Development, 2012). Moreover, the literature, both internationally and in South Africa, points to delays or outright failure by professionals working with addiction in applying current and updated understandings to their treatment programmes (Bowles et al., 2011; Perl, 2011; Toche-Manley, Grissom, Dietzen \& Sangsland, 2011). These factors impact upon the efficacy of treatment and raise issues regarding professional ethics that require a commitment to offering the best treatment to clients. The aims of the study were to investigate whether in-patients who had been diagnosed with SUD and had been admitted to three drug treatment centres in Durban, South Africa, experienced multiple addictions and if their treatment programmes appropriately assessed and managed these issues. It was hoped that the findings would add to knowledge about addiction and yield specific recommendations regarding its assessment and treatment in the South African context.

\section{RESEARCH METHODS}

\section{Research design}

This study utilised the mixed-methods approach and the concurrent embedded strategy (Creswell, 2009) was chosen as the specific research design, as explained in Table 1 below.

\section{TABLE 1 \\ MIXED METHODS RESEARCH DESIGN: CONCURRENT EMBEDDED STRATEGY}

\begin{tabular}{|c|c|c|}
\hline Analysis & Sampling & Data collection \\
\hline $\begin{array}{l}\text { Answers and comments } \\
\text { were transcribed, analysed } \\
\text { and coded into themes using } \\
\text { theoretical thematic analysis }\end{array}$ & $\begin{array}{l}\text { Phase 1. } n=11 \text {, } \\
\text { Qualitative tradition }\end{array}$ & \\
\hline \multirow[t]{3}{*}{$\begin{array}{l}\text { Data coded and programmed } \\
\text { into Epidata. } \\
\text { Data analysed using SPSS } \\
19 \text { statistical package }\end{array}$} & $\begin{array}{l}\text { All staff at each rehabilitation } \\
\text { centre were invited to } \\
\text { participate in a group } \\
\text { discussion. }\end{array}$ & $\begin{array}{l}\text { Group discussions held using } \\
\text { a group interview guide. Notes } \\
\text { were taken during the } \\
\text { sessions. }\end{array}$ \\
\hline & $\begin{array}{l}\text { Phase } 2 . \mathrm{n}=123 \\
\text { Quantitative tradition }\end{array}$ & \\
\hline & $\begin{array}{l}\text { All in-patients admitted to } \\
\text { each rehabilitation centre } \\
\text { were approached to } \\
\text { participate in screening. } \\
\text { Two proposed exceptions: } \\
\text { severe mental illness and } \\
\text { admission for an addiction } \\
\text { other than substances }\end{array}$ & $\begin{array}{l}\text { Self-administered } \\
\text { Questionnaire with } 3 \\
\text { elements: } \\
\text { 1. Biographical and drug } \\
\text { history } \\
\text { 2. Self-test for gambling } \\
\text { 3. Self-test for sex addiction } \\
\text { Perusal of participants' } \\
\text { medical records }\end{array}$ \\
\hline
\end{tabular}


This approach is characterised by the pragmatic combination of research methods from within or between the quantitative and qualitative paradigms. The goal is to ensure flexibility and sensitivity in addressing a research problem, thus enhancing the validity and reliability of the findings through the use of this "third paradigm" (Dures, Rumsey \& Morris, 2011:332).

The concurrent embedded strategy utilises simultaneous collection of qualitative and quantitative data with one method being primary and the other providing a secondary, supporting role in the research design. The secondary method is "embedded or nested" (Creswell, 2009:214) within the primary design and allows for different perspectives to be gained in the research endeavour. In this study the qualitative methodology was primary and the quantitative data provided another perspective on the research problem. The intention of this design was to utilise the two different types of evidence collected to enhance the understanding of the research problem. Data were collected within the same time frame, in a single phase, and were then analysed separately. The results were combined in the interpretation and compared to check for convergence or divergence. The results were presented together. The quantitative aspect of the design investigated the prevalence of sex and gambling addictions and the treatment history of the participants. These are the "how many?" and "how strong?" questions (Dures et al., 2011:333) that needed to be asked regarding MA. The qualitative aspect of the research explored how professionals treating addiction understood and treated MA asked the "what and how?" questions (Dures et al., 2011:333).

\section{Sampling and data collection}

Three drug treatment centres in the Durban metropolitan region participated in the research, all of which were registered with the Department of Social Development to provide services to persons with SUD. The broader study, mentioned earlier, consisted of three phases which were implemented concurrently over a six-week period during 2012. For the purpose of this article two of these phases are presented and discussed. The qualitative phase involved discussion groups held with professional staff at each of the three centres (participant profiles appear in Table 2). Three separate group discussions were held, one at each institution. The discussion explored staff members' understanding of MA, whether their current treatment programmes assessed for nonsubstance addictions and also enquired if or how these aspects were addressed. Sampling was purposive and all professional staff employed at the three centres were invited to participate. Three separate group discussions were held, one at each institution. A semistructured group interview guide consisting of main questions and probes was used to facilitate the group discussion. The researcher took notes from the responses provided by the professionals for each of the questions discussed. These were then transcribed, summarised, analysed and consolidated into a report. 
TABLE 2

PROFILE OF PROFESSIONALS WHO PARTICPATED IN THE STUDY

\begin{tabular}{|c|c|c|c|c|c|}
\hline Profession & Sex & Age & Educational level & $\begin{array}{c}\text { Years of } \\
\text { experience }\end{array}$ & $\begin{array}{l}\text { Years of experience } \\
\text { in the field of } \\
\text { addiction }\end{array}$ \\
\hline Social Worker & $\mathrm{F}$ & 71 & $\begin{array}{l}\text { B A Social Work } \\
\text { (Honours) }\end{array}$ & 18 & 5 \\
\hline Social Worker & M & 62 & $\begin{array}{l}\text { B A Social Work } \\
\text { (Honours) }\end{array}$ & 30 & 30 \\
\hline Social Worker & $\mathrm{F}$ & 44 & $\begin{array}{l}\text { Masters (Social } \\
\text { Work) }\end{array}$ & 23 & 8 \\
\hline Social Worker & $\mathrm{F}$ & 23 & $\begin{array}{c}4 \text { year Social Work } \\
\text { Degree }\end{array}$ & 7 months & 7 months \\
\hline Social Worker & $\mathrm{F}$ & 23 & $\begin{array}{c}4 \text { year Social Work } \\
\text { Degree }\end{array}$ & 7 months & 7 months \\
\hline Social Worker & $\mathrm{F}$ & 39 & $\begin{array}{c}4 \text { year Social Work } \\
\text { Degree }\end{array}$ & 11 & 2 \\
\hline Social Worker & $\mathrm{F}$ & 33 & $\begin{array}{l}4 \text { year Social Work } \\
\text { Degree }\end{array}$ & 10 & 2 \\
\hline Social Worker & $\mathrm{F}$ & 40 & $\begin{array}{l}4 \text { year Social Work } \\
\text { Degree }\end{array}$ & 6 & 1 \\
\hline Counsellor & $\mathrm{F}$ & 37 & B A (Psychology) & 7 & 7 \\
\hline $\begin{array}{l}\text { Occupational } \\
\text { Therapist }\end{array}$ & M & 45 & Degree + Honours & 24 & 22 \\
\hline $\begin{array}{l}\text { Professional } \\
\text { Nurse }\end{array}$ & $\mathrm{F}$ & 45 & $\begin{array}{c}\text { Diploma in general } \\
\text { nursing }\end{array}$ & 20 & 9 \\
\hline
\end{tabular}

The quantitative phase, implemented during the same time-frame, involved the screening of in-patients diagnosed with SUD who were admitted to the drug treatment centres during the specific six-week time frame. Each person admitted during this time frame had an opportunity to participate in the research, in keeping with the requirements of sampling in the quantitative tradition. Three potential exclusions were specified prior to beginning the research: those who refused to participate (participation was voluntary, in keeping with the research ethics guiding the process); those who had been evaluated by the staff as being too acutely psychiatrically ill to participate; and those who were not diagnosed with SUD (e.g. they had been admitted for a gambling disorder). A total of 151 in-patients were invited to participate and 123 agreed to do so, all of whom signed consent forms. No exclusions were necessary on the basis of severe mental illness or admission for another addiction. 
TABLE 3

PROFILE OF IN-PATIENT PARTICIPANTS IN THE STUDY

\begin{tabular}{|c|c|c|c|c|c|}
\hline & Profile & $\begin{array}{c}\text { Male } \\
\mathbf{n = 9 5}\end{array}$ & $\begin{array}{c}\text { Female } \\
\mathbf{n = 2 8}\end{array}$ & $\begin{array}{c}\text { Total } \\
\mathbf{n = 1 2 3}\end{array}$ & $\begin{array}{c}\text { Total } \\
\text { Percentage }\end{array}$ \\
\hline \multirow{3}{*}{$\begin{array}{c}\text { Age Range } \\
\text { (years) }\end{array}$} & $18-20$ & 10 & 4 & 14 & $11 \%$ \\
\cline { 2 - 6 } & $21-29$ & 56 & 10 & 66 & $54 \%$ \\
\cline { 2 - 6 } & $30-39$ & 13 & 10 & 23 & $19 \%$ \\
\cline { 2 - 6 } & $40-49$ & 12 & 3 & 15 & $12 \%$ \\
\cline { 2 - 6 } & $50-59$ & 2 & 1 & 3 & $2 \%$ \\
\cline { 2 - 6 } & $60-65$ & 2 & 0 & 2 & $2 \%$ \\
\cline { 2 - 6 } Sarital & Married & 10 & 2 & 12 & $10 \%$ \\
\cline { 2 - 6 } & Divorced & 8 & 4 & 12 & $10 \%$ \\
\cline { 2 - 6 } & Separated & 2 & 4 & 6 & $5 \%$ \\
\cline { 2 - 6 } & Never Married & 75 & 18 & 93 & $75 \%$ \\
\hline \multirow{4}{*}{ Educational } & Primary & 11 & 1 & 12 & $9 \%$ \\
\cline { 2 - 6 } & Grade 8-11 & 52 & 9 & 61 & $50 \%$ \\
\cline { 2 - 6 } & Matric & 26 & 8 & 34 & $28 \%$ \\
\cline { 2 - 6 } & Diploma & 4 & 8 & 12 & $10 \%$ \\
\cline { 2 - 6 } & Degree & 2 & 2 & 4 & $3 \%$ \\
\hline
\end{tabular}

In terms of racial profiles, $35 \%$ of participants were African, $12 \%$ were Coloured, $20 \%$ were Indian and $33 \%$ were White.

During data collection the in-patient participants were seen in groups of approximately eight at a time. The purpose of the research was explained to them and they completed the self-administered questionnaire (SAQ) and the screening tests for problem gambling and sex addiction. The researcher was present throughout to answer and clarify any questions.

\section{Research instruments}

A semi-structured group interview guide comprising main questions and probes was used in the first phase to guide the discussion group with the professional staff, and the answers were manually recorded by the researcher. The topics discussed were based on the research questions that guided the study, namely to explore the views on MA held by professional staff and to determine whether the current treatment programmes offered to people with SUD assessed for and treated MA.

The in-patients who had agreed to participate completed a SAQ in which they provided biographical information, and information regarding their substance use and treatment histories. The SAQ was drawn up by the researcher and asked for information in keeping with the aims of the research. Data regarding the participants' age, sex, employment, marital status, number of children and sexual orientation were gathered. Information regarding other addicts in the family and the participants' drug use history, previous exposures to treatment and period of sobriety after discharge was also sought. This SAQ was tested via a pilot study at one of the participating drug treatment centres during 2011 
and after that the questions were slightly modified to make them easier to understand. The in-patients also completed two screening tests to assess for problem gambling and sex addiction. The screening tests used were the Problem Gambling Screening Inventory (PGSI) (Bellringer et al., 2008) and the Revised Sex Addiction Screening Test (RSAST) (Carnes et al., 2010). The core test and the test for internet sex addiction (a total of 26 items) were administered to the participants. These tests were selected because they were acknowledged as valid and reliable instruments to screen for these addictions (Hodgins et al., 2011; Holtgraves, 2009; Hook et al., 2010; Orford et al., 2010).

\section{Data nalysis}

The data collected from the professional staff were analysed manually using thematic analysis and implementing the processes outlined by Braun and Clarke (2006) and De Vos (2005). Familiarisation with the data was facilitated by the fact that the first author personally conducted the group discussions and recorded participant responses. We studied the data for similarities and differences in these responses, which were coded to form broad themes. The themes were collated and analysed to answer the research questions regarding knowledge of different addictions, assessments and their treatment in keeping with the objectives of the research.

The SAQs received from the 123 in-patient participants were coded and entered into Epidata and analysed via SPSS 19. Data were analysed for trends and correlations in accordance with the research objectives. The information sheet yielded an overview of the characteristics of the participants with regard to their biographical information, data on patterns of drug use and their treatment history. The two assessment instruments were scored to ascertain whether the participant was positive/at risk/negative for a gambling disorder and positive or negative sex addiction and these results were coded into Epidata.

\section{Ethical considerations}

This study was undertaken utilising the University of KwaZulu-Natal Codes of Conduct for Research guidelines (UKZN, 2008). Ethical clearance for this study was obtained from the Human and Social Sciences' Ethical Committee at UKZN. Permission to conduct the research was obtained from the management of the institutions. All participants had their rights as research subjects explained to them and they signed informed consent forms before their participation, as per the ethical protocols that guided the study. All participation was voluntary and the identity of the centres and the participants was kept confidential. The data have been securely stored.

\section{FINDINGS}

The findings are presented first and are discussed in the next section. To ensure clarity in reporting, staff at the centres are referred to as professionals and the in-patients are referred to as participants.

\section{Current treatment programmes and staff knowledge}

In all three groups the professional staff expressed interest in the concept of MA and none had previously encountered Carnes' (2008) work regarding the four categories of 
addictions. None of the professionals in this study, including the social workers who were responsible for conducting the intake interviews, had received any training regarding addictions other than substance addiction and most felt that they needed access to updated information on this topic. Many expressed concern that their knowledge about addiction was outdated; one expressed the view that they were "working in the dark age", which reflected the views of many of the professionals. Budget constraints were listed as a major challenge in obtaining updated knowledge and were frequently listed as a challenge that impacted negatively upon the treatment programmes.

Across all three groups the responses by the professionals revealed that the drug treatment centres did not conduct formal assessments for addictions other than to substances. In fact, some professionals discussed the problem of there being no budget to purchase drug-testing kits, so they could not monitor whether their in-patients were using drugs during their stay at the treatment centre. In the discussion groups most of the professionals were aware of some of the process addictions, especially sex and gambling, and several also described codependent relationships as an addiction that they regularly encountered. All the professionals stated that they had, at some point, counselled clients who admitted to having sex and gambling addictions. They only focused on these addictions if the clients raised these as a concern during the consultations. One social worker explained that her drug treatment centre asked about gambling on their intake form and only addressed this issue in individual counselling if the in-patient had answered in the affirmative. Two of the centres briefly covered the issue of cross-addiction (mainly to other substances), but they also mentioned some process addictions (especially sex and gambling) in their groupwork programmes. One professional commented that at her centre, the current treatment programme was "too full" to accommodate information on MA, a sentiment that was echoed by a few other participants across the three centres.

\section{Prevalence of sex and gambling addictions amongst the participants}

The research revealed a substantial presence of problem gambling and sex addiction amongst the in-patient participants, as depicted in Table 4.

\section{TABLE 4}

THE PREVALENCE OF SEX AND GAMBLING ADDICTIONS (N=123)

\begin{tabular}{|c|c|c|c|c|c|c|}
\hline Addiction & $\begin{array}{c}\text { Number } \\
\text { of } \\
\text { positive } \\
\text { males } \\
\text { (n=95) }\end{array}$ & $\begin{array}{c}\text { Number } \\
\text { of } \\
\text { positive } \\
\text { females } \\
\text { (n=28) }\end{array}$ & $\begin{array}{c}\text { Number of } \\
\text { males 'at } \\
\text { risk' for } \\
\text { gambling } \\
\text { addiction }\end{array}$ & $\begin{array}{c}\text { Number of } \\
\text { females 'at } \\
\text { risk' for } \\
\text { gambling } \\
\text { addiction }\end{array}$ & $\begin{array}{c}\text { Total } \\
\text { number } \\
\text { of } \\
\text { Males }\end{array}$ & $\begin{array}{c}\text { Total } \\
\text { number of } \\
\text { Females }\end{array}$ \\
\hline Gambling & 23 & 5 & 13 & 4 & 36 & 9 \\
\hline $\begin{array}{c}\text { Core sex } \\
\text { addiction }\end{array}$ & 38 & 11 & N/A & N/A & 38 & 11 \\
\hline $\begin{array}{c}\text { Internet sex } \\
\text { addiction }\end{array}$ & 33 & 4 & N/A & N/A & 33 & 4 \\
\hline
\end{tabular}


Many of the participants who were evaluated as positive for problem gambling scored in excess of 20 out of a total score of 27 on the PGSI (where a score of eight and above was the threshold for diagnosing problem gambling). This indicated that they had experienced many negative consequences from their gambling and had a high probability of having a severe gambling disorder (APA, 2013; Bellringer et al., 2008). In total $37 \%$ of the sample presented with some issues regarding problem gambling (now termed gambling disorder in the DSM-5, 2013, incorporating the two categories of problem and pathological gambling). All but one of the participants with problem gambling issues also presented with histories of poly-substance abuse. There was no statistically significant difference between males and females and the presence of problem gambling when the Pearson's chi-square test was applied to the data.

In terms of scores for the R-SAST, there was a very strong association between sex and internet sex addictions, with $\mathrm{p}<0,005$. The sample was tested to examine the relationship between age group and internet sex addiction. There was a statistically significant relationship between these two factors, with $67 \%$ of internet sexual addiction occurring in the 21-25 year age group for both males and females, $(p=0,03)$. No such relationship existed between age and the other two addictions, namely, problem gambling or sex addiction. All the participants with sex addictions had histories of polysubstance use.

Thirty participants ( $24 \%$ of the sample) were screened as positive or "at risk" for both problem gambling and sex addiction and/or internet sex addiction. There was a statistically significant relationship between sex addiction and problem gambling for males $(p<0.01)$, but not for females $(p=0.35)$. Thus there was a high probability that if a male had problem gambling, he was also at risk of having issues with sex addiction.

\section{Previous treatment exposure and outcomes}

Forty-four percent of participants in this study had received previous treatment for SUDs and the number of previous in-patient admissions to drug treatment centres ranged from one to eight prior admissions. The percentage of women who had received previous treatment was slightly higher, with half of the 28 women reporting previous in-patient admissions, as opposed to 40 of the 95 men (42\%). However, the males reported more admissions than the females, having had an average of three or more in-patient admissions. Nine of the 14 women reported one previous admission for treatment of their addiction. The 21-29 year age group was the group that listed the most previous exposures to treatment.

Responses received about the period of sobriety attained after completing treatment were of concern. Some $85 \%$ of the sample, both male and female, reported relapsing within one week to one month after being discharged from the rehabilitation centre. During the informal discussions when administering the SAQ around a quarter stated that they had used drugs when previously admitted to a drug treatment centre, and several shared anecdotes that they had been introduced to and had used new drugs whilst in treatment. Only eight of the 54 participants (15\%) who had received previous treatment, five males 
and three females, reported maintaining a year or more than a year of sobriety after discharge, which most commonly occurred after the second admission for treatment.

\section{DISCUSSION}

\section{Staff knowledge about addiction}

The findings revealed that most of the professionals were concerned that their knowledge about addiction was out-dated, as were their treatment programmes. This was apparent in the discussions, when they certainly demonstrated very limited knowledge of MA beyond a few process addictions and were unaware of the existence of screening tests to detect the presence of gambling and sex addictions. These responses were consistent with the fact that most professionals indicated that they had limited or no knowledge of recent research on addiction. These findings raise concerns about the treatment programmes being offered at the centres: if the staff are not kept abreast of current trends in the field of addiction, how will this influence the treatment that they offer? Bowles et al. (2011) expressed similar concerns in their review of the management of drug treatment centres and noted that neither staff nor management saw the need to prioritise updating their programmes. However, in the present study the professionals were interested in updating their knowledge and skills as well as the treatment offered, but limited budgets were cited as a barrier to achieving this. A certain level of apathy was detected among the staff, who listed other concerns such as the state of poor repair of some of the facilities and poor working conditions as factors that challenged their ability to offer effective services to their clients. The general feeling was that it was the employers' role to take responsibility for their further training.

\section{Assessment of multiple addictions}

The findings highlighted that routine screening procedures at the drug treatment centres did not include assessments for additional non-substance addictions. This finding is important, given that more than half of the in-patient participants in this study (54\%) had either a gambling or sex addiction as measured by the tests administered to them, and nearly a quarter of them were screened as being positive for both addictions. As pointed out by Carnes et al. (2005), failure to address the full spectrum of the person's addictive illness is a fundamental reason for poor response rates to treatment. In fact, when giving feedback to participants, many were surprised to discover that their gambling or sexual behaviour was either problematic or potentially problematic. These responses could have been part of the denial that characterises addiction (Flores, 2004). Another reason for this lack of awareness among the male participants was their perception that their sexual behaviour was normal. None of the women who tested in the positive range for sex addiction had regarded their sexual behaviour as normal. All of them expressed concern about their behaviours.

Some participants stated that they had been encouraged to gamble by their families to assist them in their efforts to abstain from substance use. This indicates a need for family involvement in treatment as well as the important role of preventive education about addiction. While families may be well meaning, they need to be well informed in order 
to provide appropriate support and assistance to substance abusers. This finding also raises issues regarding different perceptions of addiction and gender: for men to gamble and act out sexually was more acceptable than for women, who felt more stigma than the male in-patient participants. It is important to note that if the addiction treatment programme fails to recognise or treat process addictions, it should not be surprising if the in-patients do not recognise other 'excessive appetites' (Orford, 1985, 2000) as being part of their addiction.

Given that other addictions were neither being screened nor assessed, they would only have been addressed and discussed with the patient if he/she either presented with issues regarding that addiction (such as being seen to be bulimic), or if the patient disclosed this addiction during treatment. However, given that the current programmes were primarily or exclusively focused upon substance use, it is unclear how these additional addictions would be addressed by the drug treatment centre. Relying upon patient disclosure is problematic in two ways. First, as was demonstrated in this study, many patients did not realise that they had an addiction to sex or gambling. The second problem was that, even if a patient was aware that they had a problem, it is likely that they could have been too embarrassed or ashamed to discuss this issue whilst in treatment. This is particularly relevant for sex addiction, which is highly stigmatised (Herring, 2011). Furthermoe, if the addict was unaware that their gambling, sexual behaviour, spending, eating, relationship patterns and emotional states were also part of their addiction, they would be at greater risk of replacing their drug use with these other addictive coping strategies. The findings in this study suggest that assessment of other addictions is neglected in current addiction treatment programmes and is an aspect that needs to be addressed.

\section{Treatment}

In-patient participants who had previously received treatment for SUD reported a poor response to it, with most relapsing soon (within one month) after discharge. A further concern was that it was clear from the informal discussions held whilst administering the SAQs that several of the participants had used drugs whilst in treatment and that some had been introduced to or learned about other drugs which they had used after discharge. They were aware that certain centres did not test them for substance use whilst admitted for treatment and believed that if they used drugs during their stay, there was little likelihood of this being detected. This would obviously make it more difficult for an inpatient who was craving substances to abstain from them, despite their participation in a drug treatment programme. The professionals expressed deep concern where there was no budget to test for substance use amongst in-patients, as they were aware of the temptation to which their in-patients could be exposed.

Another issue that emerged was that most in-patients, upon discharge, had not continued with aftercare either at the drug treatment centre or with other groups such as Alcoholics Anonymous, or Narcotics Anonymous. The lack of follow-up and continuation of treatment as out-patients may be linked to the high relapse rates mentioned by participants. In fact, the literature is clear that attendance at after-care services improves 
treatment outcomes (Flores, 2004; McCauley, 2009). Finally, the fact that none of the centres conducts any research on the treatment outcomes confirms the trends found locally (Bowles et al., 2011) and internationally (Toche-Manley et al., 2011), that research and ongoing training of staff are neglected components of staff development. Engaging in research and/or being informed on current findings and literature on substance use, assessments and trends in treatment for substance use and MA could assist in improving treatment outcomes.

\section{IMPLICATIONS FOR PRACTICE AND RESEARCH}

The findings have significant implications for social workers and other professionals involved at various levels of assessment and treatment of in-patients and their families. The majority of in-patients who participated in the research had a sex and/or gambling addiction that had not been detected by the drug treatment centre into which they had been admitted. Those who had previously received treatment $(44 \%)$ had generally relapsed within the first month after leaving the drug treatment centre. Although recommendations made are based on the findings with drug treatment centres that participated in this study, these findings may have implications for other centres providing services to people with SUD. There is clearly a need to review and update assessment procedures and treatment programmes. Programmes which focus mostly upon substances to the exclusion of the rest of the addiction spectrum are not adequately meeting the needs and addressing the profile of the people they are treating. This must be seen against the background of international research which indicates that people seeking treatment for one addiction have a strong possibility of having at least one other addiction (Carnes, 2008; Sussman et al., 2011) and this study has confirmed this trend.

This study found that at only one of the three centres that participated in the research staff presented information on the neurobiology of addictions which is an important part of patient education, as it educates the in-patients about the mechanisms underlying all addictions (McCauley, 2009). It is suggested that this practice be adopted at all treatment facilities as in-patient education about addiction is crucial to their recovery. Information given during treatment needs to include discussions about the full spectrum of addictions and this could be given in both individual and group-work interventions with in-patients and their families. Social workers are active in implementing such interventions and if they are equipped with relevant information they could offer a more holistic programme that could address the broader needs of the patients. Secondly, because of the high prevalence of sex and gambling addictions found amongst substance users in this study, which confirmed the finding of international research (Carnes, 2008; Sussman et al., 2011), it is felt that in-patients should be routinely screened for these two process addictions during the initial assessment phase. It is recommended that staff receive training in the use of the tools to assess for gambling disorders and sex addiction, as well as being alert for other manifestations of addiction, such as issues with money, eating, work, exercise and relationships. If these additional addictions are identified, appropriate treatment programmes should be developed. Staff expressed a strong desire for additional training in MA and this could improve the treatment offered to in-patients in drug treatment centres. Given the prevalence of addiction in mental health, a strong case 
can be made that all professionals working in this field could benefit from training about MA.

Further research is necessary to ascertain if the high prevalence of additional addictions amongst people diagnosed with SUD is also present in other populations undergoing other forms of treatment, such as out-patients or people attending self-help groups such as Alcoholics Anonymous and Narcotics Anonymous. This would help to clarify if people requiring in-patient treatment for SUD present an especially at-risk category for MA, or if they are part of a broader group of people, all of whom share the vulnerability. Similar research conducted in other parts of the country may establish if this situation prevails nationwide. Further research could also be conducted with groups who have a different primary diagnosis, such as those with gambling disorders.

\section{LIMITATIONS OF THE STUDY}

Because of its exploratory nature the research process was confined to three in-patient facilities in the Durban metropolitan area of South Africa, and the sample size for the survey was limited to 11 professional staff and to 123 in-patient participants. It did not include individuals receiving out-patient treatment or attending self-help groups such as Alcoholics Anonymous. As indicated, this is an area for further research.

The stigma attached to addiction could have resulted in people not being honest in their responses. There are issues of the social desirability effect, where participants could have "sanitised" their responses to make them appear less shameful or offensive. Conversely, some participants could have wanted to impress or shock the researcher with their responses. Efforts were made to overcome this potential limitation in several ways, as the first author, an experienced social worker, conducted all of the research personally. The research design incorporated triangulation of data to increase the validity of the findings. Triangulation occurred through use of the phases in the research design and information from each phase was cross-checked against the other.

\section{CONCLUSION}

As emphasised in this paper, addiction is a major public health and social concern in South Africa that in its many manifestations is having a significant impact in creating disability, disharmony and broader social disease. It is vital that the current exclusive focus on substance use that was noted in current programmes offered at the drug treatment centres be extended to incorporate a broad spectrum of behaviours, in keeping with the latest research on the topic. It has been argued that failure to address the full spectrum of addictions is one of the reasons for the high failure rate of treatment. The findings in this study point to the need for further research in this area to ascertain the extent of co-addictions amongst a variety of populations diagnosed with addictive disorders. They also suggest that assessment and treatment of SUD need to be updated in line with research findings to afford the best possible treatment for an illness that is "cunning, baffling and powerful" (Alcoholics Anonymous, 2001:58-59). 


\section{REFERENCES}

ALCOHOLICS ANONYMOUS. 2001. Big book online. [Online] Available: http://www.aa.org.bigbookonline [Accessed: 07.11.2011].

APA (AMERICAN PSYCHIATRIC ASSOCIATION). 2013. Diagnostic and statistical manual of mental disorders $\left(5^{\text {th }}\right.$ ed). Washington, DC: American Psychiatric Association.

BELlRINGER, M., ABBOTT, M., COOMBES, R., GARRETT, N. \& VOLBERG, R. 2008. Problem gambling assessment and screening instruments. Phase two: final report. Wellington: Ministry of Health, Wellington, New Zealand.

BOWLES, S., LOUW, J. \& MYERS, B. 2011. Perceptions of organizational functioning in substance abuse treatment facilities in South Africa. International Journal of Mental Health \& Addiction, 9(3):308-319. doi:10.1007/s11469-010-9285-2.

BRADSHAW, J. 2005. Healing the shame that binds you $\left(2^{\text {nd }}\right.$ ed). Florida: Health Communications Inc.

BRAUN, V. \& CLARKE, V. 2006. Using thematic analysis in psychology. Qualitative research in Psychology, 3(2):77-101,101. doi:10.1191/147808706q063oa.

BULWER, M. 2003. Treating gambling addiction: a psychological study in the South African context. Pretoria: UNISA. Master of Arts in Social Science ed. [Online] Available: http://search.ebscohost.com/login.aspx?direct=true\&db=awn\&AN=NX0 171 431\&site=ehost-live [Retrieved: 05.05.2012].

CARNES, P.J. 1991. Don't call it love: recovery from sexual addiction. New York: Bantam Books.

CARNES, P.J. 2008. Facing the shadows. Facing the shadow: understanding multiple addictions. Conference proceedings, Indaba Hotel, Johannesburg.

CARNES, P.J., MURRAY, R.E. \& CHARPENTIER, L. 2005. Bargains with chaos: sex addicts and Addiction Interaction Disorder. Sexual Addiction \& Compulsivity, 12(2):79-120. doi:10.1080/10720160500201371.

CARNES, P.J., DELMINICO, D. \& GRIFFIN, E. 2007. In the shadows of the net: breaking free of compulsive online sexual behaviour $\left(2^{\text {nd }} \mathrm{ed}\right)$. Center City, Minnesota: Hazelden.

CARNES, P., GREEN, B. \& CARNES, S. 2010. The same yet different: refocusing the Sexual Addiction Screening Test (SAST) to reflect orientation and fender. Sexual Addiction \& Compulsivity, 17(1):7-30. doi:10.1080/10720161003604087.

CRESWELL, J.W. 2009. Research design: quantitative, qualitative and mixed methods approaches $\left(3^{\text {rd }}\right.$ ed). Los Angeles: Sage Publications.

DEPARTMENT OF SOCIAL DEVELOPMENT, 2012. (last update). National Drug Master Plan 2012-2016. First Draft, 2nd Revision. [Online] Available: https://www.daggacouple.co.za [Accessed: 15/02/2013]. 
DE VOS, A.S. 2005. Combined quantitative and qualitative approach. In: DE VOS, A.S., STRYDOM, H., FOUCHÉ, C.B. \& DELPORT, C.S.L. (eds) Research at grass roots: for the social sciences and human service professions $\left(3^{\text {rd }}\right.$ ed $)$. Pretoria: Van Schaik Publishers.

DOWEIKO, H. 2006. Concepts of chemical dependency $\left(6^{\text {th }}\right.$ ed). Belmont: Thomson. DURES, E., RUMSAY, N. \& MORRIS, M. 2011. Mixed methods in health: 2011: Psychology: theoretical and practical considerations of the third paradigm. Journal of Health Psychology, 16:322-341. doi:http://hpqsagepub.com.

ERIKSON, C. 2009. The Neurobiology of addiction. Center City, Minnesota: Hazeldon. FLORES, P.J. 2004. Addiction as an attachment disorder. Maryland.: Jason Aronson. FRASCELLA, J., POTENZA, M.N., BROWN, L.L. \& CHILDRESS, A.R. 2010. Shared brain vulnerabilities open the way for nonsubstance addictions: carving addiction at a new joint? Annals of the New York Academy of Sciences, 1187(1):294-315. doi:10.1111/j.1749-6632.2009.05420.x.

GREEN, A.B., CARNES, S., CARNES, P.J. \& WEINMAN, E.A. 2012. Cybersex addiction patterns in a clinical sample of homosexual, heterosexual and bisexual men and women. Sexual Addiction and Compulsivity, 19:77-98. doi: 10.1080/ 10720162.2012.658343.

GRIFFITHS, M. 2012. Internet sex addiction: a review of empirical research. Addiction Research and Theory, 20(2):111-124. doi:10.3109/16066359.2011.588351.

HERRING, B. 2011. A 'Sex addict' by any other name hurts the same. Sexual Addiction \& Compulsivity, 18(2):57-60. doi:10.1080/10720162.2011.579037

HODGINS, D.C., STEA, J.N. \& GRANT, J.E. 2011. Gambling disorders. The Lancet, 378(9806):1874-1884.

HOFFMANN, B. 2011. Pathological gambling - an example of non-substance related addiction. Trakia Journal of Sciences, 9(4):69-74. [Online] Available: http://search.ebscohost.com/login.aspx?direct=true \&db=a9h\&AN=69931454\&site=ehos t-live.

HOLTGRAVES, T. 2009. Evaluating the Problem Gambling Severity Index. Journal of Gambling Studies, 25(1):105-120. doi:10.1007/s10899-008-9107-7.

HOOK, J.N., HOOK, J.P., DAVIS, D.E., WORTHINGTON, E.L. \& PENBERTHY, J.K. 2010. Measuring sexual addiction and compulsivity: a critical review of instruments. Journal of Sex \& Marital Therapy, 36(3):227-260. doi:10.1080/ 00926231003719673.

MacLAREN, V.V. \& BEST, L.A. 2010. Multiple addictive behaviors in young adults: Student norms for the Shorter PROMIS Questionnaire. Addictive Behaviors, 35(3):252255. doi: 1010161/j.addbeh2009.09.023.

MAKUYANA, I. 2013. Drugs' Scary Story. The New Age, 1, 6 June. 
McCAULEY, K. 2009. Pleasure unwoven: a personal journey about addiction. Utah: Institute of Addiction Study.

NJUHO, P. \& DAVIDS, A. 2011. Extent and influence of recreational drug use on men and women aged 15 years and older in South Africa. African Journal of Drug and Alcohol Studies, 9(1).

ORFORD, J. 2000. Excessive appetites: a psychological view of addictions ( $\left.2^{\text {nd }} \mathrm{ed}\right)$. Chichester: John Wiley and Sons.

ORFORD, J. 1985. Excessive appetites: a psychological view of addictions. Chichester: John Wiley and Sons.

ORFORD, J., WARDLE, H., GRIFFITHS, M., SPROSTON, K. \& ERENS, B. 2010. PGSI and DSM-IV in the 2007 British Gambling Prevalence Survey: reliability, item response, factor structure and inter-scale agreement. International Gambling Studies, 10(1):31-44. doi:org.1080/14459790903567132.

PERL, H.I. 2011. Addicted to discovery: does the quest for new knowledge hinder practice improvement? Addictive Behaviors, 36(6):590-596.

SCHNEIDER, J.P. 2005. Addiction is addiction is addiction. Sexual Addiction \& Compulsivity, 12(2-3):75-77. doi:10.1080/10720160500203468.

SEGGIE, J. 2012. Alcohol and South Africa's youth. SAMJ: South African Medical Journal, 102(7):587-587.

SHAFFER, H., LAPLANTE, D., LABRIE, R., KIDMAN, R., DONATO, A. \& STANTON, M. 2004. Toward a Syndrome Model of Addiction: multiple expressions, common etiology. Harvard Review of Psychiatry, 12(6):367-374. doi:10.1080/10673220490905705.

SUSSMAN, S., LISHA, N. \& GRIFFITHS, M. 2011. Prevalence of the addictions: a problem of the majority or the minority? Evaluation \& the Health Professions, 34(1):3-56. doi:10.117710163278710380124.

TOCHE-MANLEY, L., GRISSOM, G., DIETZEN, L. \& SANGSLAND, S. 2011. Translating addictions research into evidence-based practice: the Polaris CD outcomes management system. Addictive Behaviors, 36(6):601-607. doi:10.1016/j.addbeh. 2011.01.019.

UKZN (UNIVERSITY OF KWAZULU-NATAL). 2008. Guidelines for completing the human and social sciences research application form. [Online] Available: www.research.ukzn.ac.za/researchethics/human_social_sciences_ethics.apx [Accessed: 25/05/2011].

VAN HEERDEN, M.S., GRIMSRUD, A.T., SEEDAT, S., MYER, L., WILLIAMS, D.R. \& STEIN, D.J. 2009. Patterns of substance use in South Africa: results from the South African stress and health study. SAMJ: South African Medical Journal, 99(5):358-366. 
VOS, T., FLAXMAN, A.D., NAGHAVI, M. \& MURRAY, C.J. 2012. Years lived with disability (YLDs) for 1160 sequelae of 289 diseases and injuries 1990-2010: a systematic analysis for the global burden of disease study 2010. The Lancet, 380(9859), 2163-2196. doi:http://dx.doi.org/10.1016/S0140-6736(12)61729-2.

WHO (WORLD HEALTH ORGANISATION). 2014. Global Status Report in Alcohol and Health. [Online] Available: www.who.substance_abuse/publications/ global_alcohol_report/en. [Accessed: 21/07/2014].

Dr Helen Keen, Social Worker in Private Practice, Durban; Dr Reshma Sathiparsad, Senior Research Associate, School of Applied Human Sciences, University of KwaZulu-Natal; Prof Myra Taylor, Senior Researcher, School of Nursing and Public Health University of KwaZulu-Natal, Durban. South Africa. 